\title{
Fermented Wheat Germ Extract
}

National Cancer Institute

\section{Source}

National Cancer Institute. Fermented Wheat Germ Extract. NCI Thesaurus. Code C64763.

An extract of fermented wheat germ containing a concentrated, standardized amount of methoxy-substituted benzoquinones with immunomodulatory and potential antineoplastic activities. Fermented wheat germ extract (FWGE) inhibits the activities of several enzymes involved in de novo nucleic acid synthesis and in supplying the dNTP pool required for DNA replication. This agent also induces caspase-3- mediated inactivation of poly(ADP)ribose polymerase (PARP), a key enzyme in DNA repair that is overexpressed in many cancers; cleavage of PARP prevents DNA repair and induces apoptosis. The benzoquinones may contribute to the immunomodulatory effects of FWGE, down-regulating major histocompatibility complex class I (MHC-1) protein on the surface of cancer cells, allowing natural killer (NK) cell surveillance; and up-regulating the expression of intracellular adhesion molecule 1 (ICAM-1) on tumor endothelial cells. 